\title{
Rare Primary Diffuse Large B-Cell Lymphoma of a Male Breast
}

\author{
Hani Alothaid1, Umama Yezdani², Mahmoud M. Habibullah³, Saad Saeed Alamri, \\ Mazen M. Ghaith ${ }^{5}$, Mohammad Gayoor Khan ${ }^{6 *}$
}

\begin{abstract}
${ }^{1}$ Department of Basic Medical Sciences, Faculty of Applied Medical Sciences, Al-Baha University, Al-Baha, Saudi Arabia ${ }^{2}$ Department of Pharmacy Practice, MRM College of Pharmacy, Hyderabad, India

${ }^{3}$ Medical Laboratory Technology Department, Faculty of Applied Medical Sciences, Jazan University, Jazan, Saudi Arabia ${ }^{4}$ Research Center, King Fahad Medical City, Riyadh, Saudi Arabia

${ }^{5}$ Laboratory Medicine Department, Faculty of Applied Medical Science, Umm Al-Qura University, Makkah, Saudi Arabia ${ }^{6}$ UCB Unit, Department of Pharmacovigilance, Bioclinica, Mysore, India
\end{abstract}

Email: halothaid@bu.edu.sa, umamayezdani6@gmail.com, mhabibullah@jazanu.edu.sa, salamri@kfmc.med.sa, mmghaith@uqu.edu.sa, ‘gayoor.dips.pharmacy@gmail.com, ${ }^{\star}$ Gayoor.khan@bioclinica.com

How to cite this paper: Alothaid, H., Yezdani, U., Habibullah, M.M., Alamri, S.S., Ghaith, M.M. and Khan, M.G. (2021) Rare Primary Diffuse Large B-Cell Lymphoma of a Male Breast. Case Reports in Clinical Medicine, 10, 99-107.

https://doi.org/10.4236/crcm.2021.104012

Received: February 2, 2021

Accepted: April 13, 2021

Published: April 16, 2021

Copyright $\odot 2021$ by author(s) and Scientific Research Publishing Inc. This work is licensed under the Creative Commons Attribution International License (CC BY 4.0).

http://creativecommons.org/licenses/by/4.0/

(c) (i) Open Access

\begin{abstract}
Background: Breast lymphomas are typical extranodal types of lymphoma, also known as Extranodal-lymphoma (ENL), which occur extremely infrequently, aggregating into a very small proportion of malignant breast tumors. The rarity of breast lymphomas is attributed to the scant lymphoid tissue content of the chest wall. Aims of Study: This case report is aimed at providing an up-to-date review of the literature on breast lymphomas for clinicians to, therefore, consider the possibility of this disease entity while treating a breast mass. Case Presentation: A case was reported of a 52-year man with chief mammary non-Hodgkin breast ENL when fine-needle aspiration cytology (FNAC) was not leading to a firm conclusion or result. Following an incisional biopsy, he was found to have a primary breast lymphoma. Later, the patient was diagnosed with the diffuse large B-cell type of lymphoma also known as non-Hodgkin's Lymphoma (NHL). He had a complete reduction and disappearances of all the signs and symptoms of the disease after a course of neoadjuvant chemotherapy: Cyclophosphamide, Doxorubicin, Vincristine and Prednisolone (CHOP). CONCLUSION: Based on the above case presentation, it is vital for health care professionals and oncologists to recognize the disease by assessing the breast mass accurately with more entities so that proper diagnosis via core biopsy (incisional biopsy) can eliminate the PBL before further treatment is required.
\end{abstract}

\section{Keywords}

Non-Hodgkin's Lymphoma, PBL, B-Cell Lymphoma, 


\section{Introduction}

Primary breast lymphoma (PBL) is both a typical yet rare clinical entity: a very well-defined subcategory of non-Hodgkin's Lymphoma (NHL). Several reports suggest that PBL represents $0.6 \%$ of all malignant breast tumors, $1.2 \%$ of all the NHL, and 2.1\% of Extranodal-lymphomas (ENL) [1] [2] [3] [4] [5]. Most breast lymphomas are of the non-Hodgkin's type, representing approximately $70 \%$ $90 \%$ of all PBL, while diffuse large B- cell lymphomas (DLBCL) constitute $46 \%$ $71 \%$ of all PBL [6]. However, (P-NHL) Primary-NHL is one of the most frequent and hematopoietic tumors of the breast [7]

Aims of Study: This case report is aimed at providing an up-to-date review of the literature on breast lymphomas for clinicians to, therefore, consider the possibility of this disease entity while treating a breast mass.

\section{The Case Presentation}

A 52-year-old male industrial chemist was admitted to the surgical outpatients' department at a tertiary hospital with a painless left breast lump that had been evident for 8 months and had increased in size progressively. There was a darkening of the overlying skin and no nipple discharge. The patient reported remarkable weight loss and intermittent fevers over the period, but also reported no cancer history in his family. He had self-treated with herbal medications for some months prior to arriving at the tertiary hospital. Physical examination revealed a middle-aged man, who appeared chronically ill and cachectic. The left breast was diffusely enlarged with a $\sim 4 \mathrm{~cm} \times 3 \mathrm{~cm}$ mass located in the center portion with a darkening of the overlying skin. He also had discrete tiny ulcers in the nipple-areolar complex oozing a small amount of serosanguinous fluids with a few other lymph nodes such as Axillary lymph nodes. FNAC revealed potential malignancy, but results were inconclusive. He subsequently had an incisional biopsy with a histopathology report, which confirmed PBL distinguished as a large B-cell type of non-Hodgkin's lymphoma. The observational photograph of the index patient is as displayed in Figure 1(a). Figure 1(b) shows the characteristic diffuse lesion as seen in the mammographic study. Figure 2 and Figure 3 show the Hematoxylin and eosin (H\&E) staining of the breast tissue and DLBCL with activated B-cell type respectively. Here, the tumor-cells are revealed as $\mathrm{CD} 3, \mathrm{CD} 5, \mathrm{CD} 15, \mathrm{CD} 30$, and $\mathrm{CK}$ negative but came out positive for CD45, CD20, CD10, BCL6 (see Figures 4(a)-(d)). The breast scan showed multiple heterochronic tiny masses of variable sizes in the middle portion of the right breast. A cranial and abdominal CT scan was essentially normal while the chest CT scan showed left pulmonary infiltrates with hilar lymphadenopathy but no pleural effusion. The biochemical profile and complete blood count were also 
typical. Subsequently, he had a total of six doses of medication of neoadjuvant chemotherapy: (CHOP)-Cyclophosphamide, Doxorubicin, Vincristine and Prednisolone, and thereafter experienced complete disease remission. He was examined at two-month intervals for approximately 18 months in the surgical outpatient clinic with a satisfactory clinical outcome, following which he requested an end to follow-up examinations.

(a)

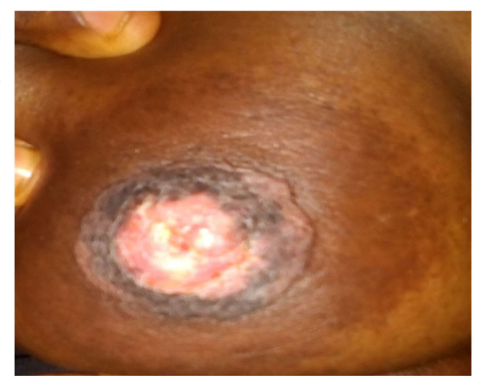

(b)

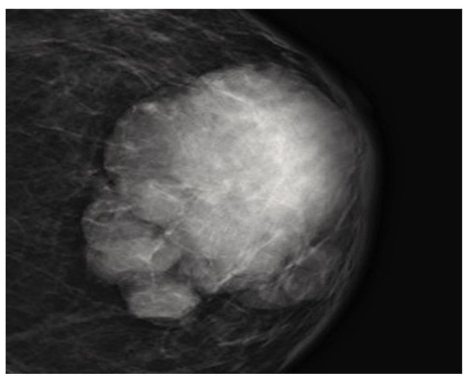

Figure 1. Clinical image of breast of the index patient displaying (a) large B-cell type; Non-Hodgkin's lymphoma (b) diffuse right breast lesion shown from mammographic study of index patient.

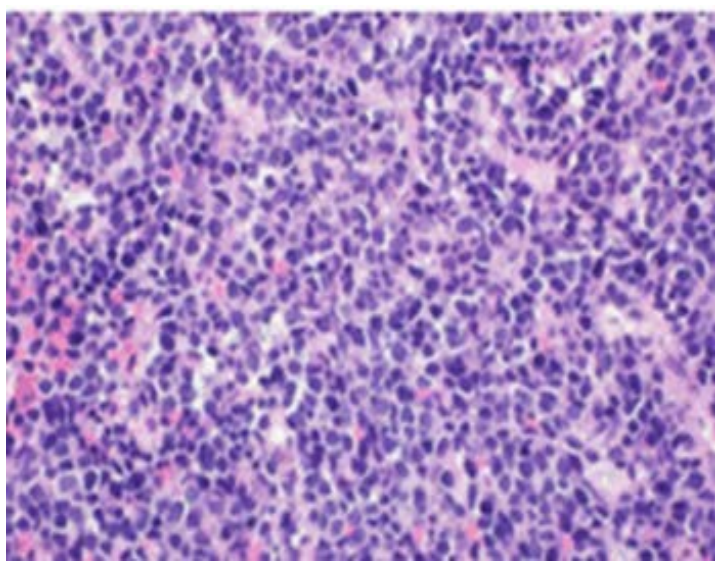

Figure 2. H\&E stain showing the histology of breast tissue from index patient at $400 \times$ magnification.

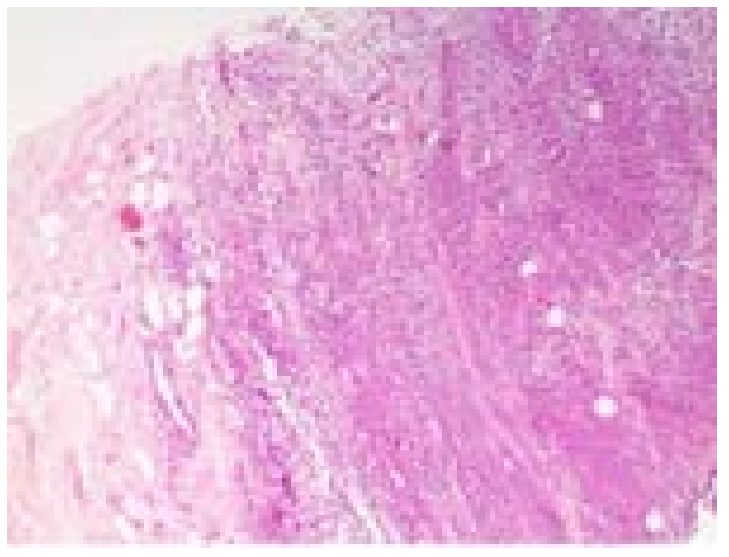

Figure 3. Diffuse large B-cell lymphomas (DLBCL) with activated B-cell type. 
(a)

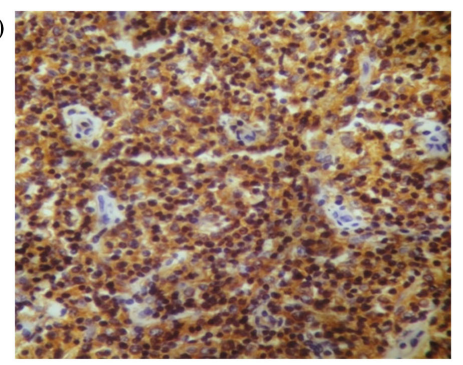

(c)

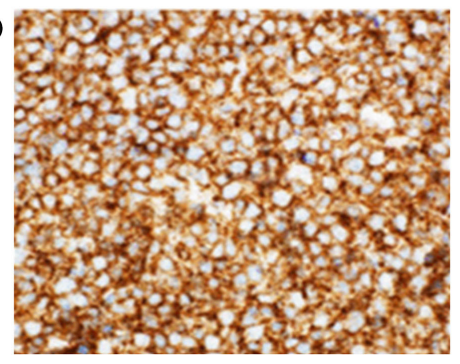

(b)

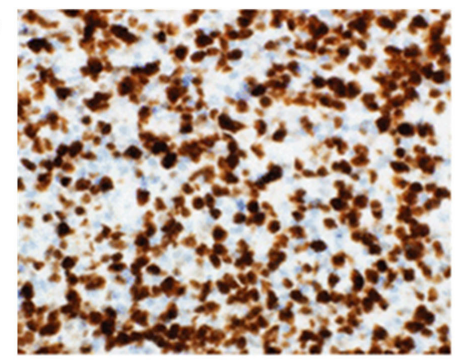

(d)

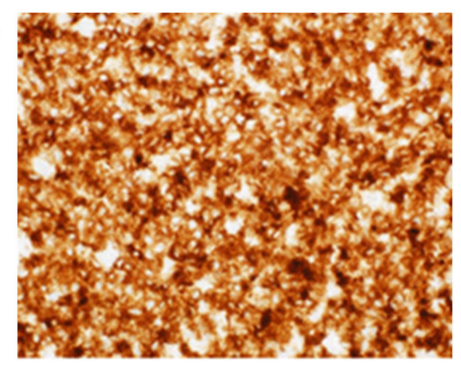

Figure 4. Antibody staining of the breast tissue to detect: (a) CD 45 (b) CD 20 (c) CD 10 (d) BCL6 (uncommon).

\section{Discussion}

The index patient is male with a lesion located on the left breast. This finding concurred with previous reports indicating that both Nodal-Lymphomas (NL) and Extranodal-Lymphomas (ENL) occur more frequently in males, with the involvement of the breast being mainly associated with females [8]. However, this finding contradicts those of other studies which reported that breast PNHL involved only the right side of the breast, and was almost entirely found in female patients. It is unclear why the right side of the breast is the most common site for these [7]. Primary-Lymphomas (PL) of the breast is generally regarded as rare, yet they remain the most frequently occurring hematopoietic breast tumor [7] [9] [10]. Physicians or oncologists treating and dealing with the carcinoma in the breast should endeavor to be fully up-to-date with knowledge regarding this entity to distinguish the signs and symptoms associated with prompt management of the condition. Indeed, the early prognosis of breast carcinoma is important for satisfactory clinical outcomes [10] [11] [12] [13]. In addition, single-breast involvement is more common, particularly in the upper-right portion of the breast [14] [15] [16] [17]. Only approximately $1 \%-14 \%$ of reported primary breast lymphoma affects both sides of the breast (bilateral) disease [18].

There have been many diagnostic criteria of primary-breast lymphoma [15]. In 1972, Wiseman and Liao defined the existence of adequate pathologic specimens as diagnostic criteria for P-NHL. There is also a very close association of the mammary tissue and lymphomatous infiltration, with no previous diagnosis of an extramammary-lymphoma, with possible ipsilateral axillary lymph node involvement [7] [15] [19]. Our patient fulfilled these criteria, and this further supports our conclusion that this was an instance of a primary breast lymphoma (PBL), and those breast-cancers, in general, are not diseases associated with the 
younger age group. Finally, PBL is most commonly seen as a palpable mass, as shown in our index patient [20] [21].

An open biopsy supported with immunophenotyping proved to be a very reliable confirmatory diagnostic tool. Tru-cut biopsies have equally distinguished the diagnosis of breast-malignancies with a good accuracy rate [22] [23]. Many radiographic detection methods, such as CT, sonography and mammography, are generally nonspecific for PBL [24] [25] [26] [27]. It should be noted that immuno-phenotyping in the diagnosis of PNH-Lymphoma of the breast is crucial, with several reports from the literature confirming that immuno-phenotyping plays a key role in evaluating and diagnosing the disease [28] [29] [30] [31] [32]. In our index patient, the histopathological diagnosis was PBL of the large B-cell type (non-Hodgkin's type). The tumor cells typing were negative for CD3, CD5, CD15, CD30, CK but were positive for CD45, CD20, CD10, and BCL6 (see Figures $4(\mathrm{a})-(\mathrm{d})$ ) with clinical evidence of distant metastasis to the lung parenchyma (T2 N0 M1).

Several treatment options are available for primary breast lymphoma, such as chemotherapy as the first preference of treatment of primary-BL, and radiation as a second preference, followed by surgery. The above-mentioned preferences can be used alone or in combination [32] [33] [34] [35]. The impact of surgeries as a treatment option for PBL is limited due to surgery requiring adequate tissue for proper diagnostic criteria and classification of the disease [31] [33]. Finally, mastectomy offers no guarantee of preventing recurrence [36]. In patients with $\mathrm{PBL}$, the survival rates are comparable with other types of lymphomas: relatively high. The likely course of the diseased condition of PBL depends mainly on the description of the abnormality of the tumor (histological-grade) [31] [37]. The International Prognostic Index (IPI) suggests predictors of survival that include 1) $\mathrm{LDH}$ levels, 2) performance status, 3) age, 4) the presence of extranodal tumors, and v) Ann Arbor staging in the prediction of 5-year survival [32] [33]. For Stage I disease, the 5-year survival rate is $89 \%$ [35]. Finally, the central nervous system [CNS] is regarded as the most typical site of relapse due to its high level of incidence and involvement based on available reports [38] [39].

\section{Conclusion}

Based on the above case presentation, it is obligatory for health care professionals and oncologists to recognize the disease by assessing the breast mass accurately with more entities to provide the possibility of distinguishing the disease via proper diagnosis, including core biopsy (incisional biopsy), and thus eliminate PBL before further treatment is required.

\section{Authors Contributions}

All authors have made substantial contributions to conception and design, acquisition of data, and analysis and interpretation of data. All authors were involved in drafting the manuscript and its critical revision. All authors have given 
final approval of the version to be published. Each author has participated sufficiently in the work to take public responsibility for appropriate portions of the content. All authors agree to be accountable for all aspects of the work in terms of ensuring that questions related to the accuracy or integrity of any part of the work were appropriately investigated and resolved.

\section{Ethical Approval}

We confirm that no ethical approval is required to publish case reports from our institutions and the collaborative hospital.

\section{Conflicts' of Interest}

The authors declare no conflicts of interest regarding the publication of this paper.

\section{References}

[1] Fruchart, C., Denoux, Y., Chasle, J., Peny, A.M., Boute, V., Ollivier, J.M., et al. (2005) High Grade Primary Breast Lymphoma: Is It a Different Clinical Entity? Breast Cancer Research and Treatment, 93, 191-198. https://doi.org/10.1007/s10549-005-5088-8

[2] Ryan, G., Martinelli, G., Kuper-Hommel, M., Tsang, R., Pruneri, G., Yuen, K., et al. (2008) Primary Diffuse Large B-Cell Lymphoma of the Breast: Prognostic Factors and Outcomes of a Study by the International Extranodal Lymphoma Study Group. Annals of Oncology: Official Journal of the European Society for Medical Oncology, 19, 233-241. https://doi.org/10.1093/annonc/mdm471

[3] Talwalkar, S.S., Miranda, R.N., Valbuena, J.R., Routbort, M.J., Martin, A.W. and Medeiros, L.J. (2008) Lymphomas Involving the Breast: A Study of 106 Cases Comparing Localized and Disseminated Neoplasms. The American Journal of Surgical Pathology, 32, 1299-309. https://doi.org/10.1097/PAS.0b013e318165eb50

[4] Validire, P., Capovilla, M., Asselain, B., Kirova, Y., Goudefroye, R., Plancher, C., et al. (2009) Primary Breast Non-Hodgkin's Lymphoma: A Large Single Center Study of Initial Characteristics, Natural History, and Prognostic Factors. American Journal of Hematology, 84, 133-139. https://doi.org/10.1002/ajh.21353

[5] Yhim, H.-Y., Kang, H.J., Choi, Y.H., Kim, S.J., Kim, W.S., Chae, Y.S., et al. (2010) Clinical Outcomes and Prognostic Factors in Patients with Breast Diffuse Large B Cell Lymphoma; Consortium for Improving Survival of Lymphoma (CISL) Study. BMC Cancer, 10, 321. https://doi.org/10.1186/1471-2407-10-321

[6] Villalón-López, J.S., Souto-del Bosque, R. and Méndez-Sashida, P.G. (2017) Primary Non-Hodgkin's Lymphoma of the Breast. A Case Report. Cirugía y Cirujanos (English Edition), 85, 70-75. https://doi.org/10.1016/j.circen.2016.12.005

[7] Jeon, H.J., Akagi, T., Hoshida, Y., Hayashi, K., Yoshino, T., Tanaka, T., et al. (1992) Primary Non-Hodgkin Malignant Lymphoma of the Breast. An Immunohistochemical Study of Seven Patients and Literature Review of 152 Patients with Breast Lymphoma in Japan. Cancer, 70, 2451-2459.

https://doi.org/10.1002/1097-0142(19921115)70:10<2451::AID-CNCR2820701011> 3.0.CO;2-B

[8] Albertini, J.J., Lyman, G.H., Cox, C., et al. (1996) Lymphatic Mapping and Sentinel Node Biopsy in the Patient with Breast Cancer. JAMA, 276, 1818-1822. https://doi.org/10.1001/jama.1996.03540220042028 
[9] Kelten, C., Kabukcu, S., Sen, N., Teke, Z., Yaren, A., Erdem, E., et al. (2009) Secondary Involvement of the Breast in T-Cell Non-Hodgkin Lymphoma, an Unusual Example Mimicking Inflammatory Breast Carcinoma. Archives of Gynecology and Obstetrics, 280, 149-152. https://doi.org/10.1007/s00404-008-0869-Z

[10] Pruthi, S., Stafyla, V.K., Phillips, S.W., Porrata, L.F. and Reynolds, C.A. (2004) Primary Mammary (Non-Hodgkin) Lymphoma Presenting as Locally Advanced Breast Cancer. Mayo Clinic Proceedings, 79, 1310-1314. https://doi.org/10.4065/79.10.1310

[11] Aviv, A., Tadmor, T. and Polliack, A. (2013) Primary Diffuse Large B-Cell Lymphoma of the Breast: Looking at Pathogenesis, Clinical Issues and Therapeutic Options. Annals of Oncology, 24, 2236-2244. https://doi.org/10.1093/annonc/mdt192

[12] Jabbour, G., El-Mabrok, G., Al-Thani, H., El-Menyar, A., Al Hijji, I. and Napaki, S. (2016) Primary Breast Lymphoma in a Woman: A Case Report and Review of the Literature. American Journal of Case Reports, 17, 97-103. https://doi.org/10.12659/AJCR.896264

[13] Uesato, M., Miyazawa, Y., Gunji, Y. and Ochiai, T. (2005) Primary Non-Hodgkin's Lymphoma of the Breast: Report of a Case with Special Reference to 380 Cases in the Japanese Literature. Breast Cancer (Tokyo, Japan), 12, 154-158. https://doi.org/10.2325/jbcs.12.154

[14] Garg, N.K., Bagul, N.B., Rubin, G. and Shah, E.F. (2008) Primary Lymphoma of the Breast Involving both Axillae with Bilateral Breast Carcinoma. World Journal of Surgical Oncology, 6, 52. https://doi.org/10.1186/1477-7819-6-52

[15] Gualco, G., Chioato, L., Harrington, W.J., Weiss, L.M. and Bacchi, C.E. (2009) Primary and Secondary T-Cell Lymphomas of the Breast: Clinico-Pathologic Features of 11 Cases. Applied Immunohistochemistry \& Molecular Morphology. AIMM, 17, 301-306. https://doi.org/10.1097/PAI.0b013e318195286d

[16] Inic, Z., Inic, M., Zegarac, M., Inic, I. and Pupic, G. (2013) Three Cases of Combined Therapy in Primary Breast Lymphoma (PBL) with Successful Outcomes. Clinical Medicine Insights: Oncology, 7, 159-163. https://doi.org/10.4137/CMO.S12044

[17] Yang, H., Lang, R.-G. and Fu, L. (2011) Primary Breast Lymphoma (PBL): A Literature Review. Clinical Oncology and Cancer Research, 8, 128. https://doi.org/10.1007/s11805-011-0570-Z

[18] Zucca, E., Conconi, A., Mughal, T.I., Sarris, A.H., Seymour, J.F., Vitolo, U., et al. (2003) Patterns of Outcome and Prognostic Factors in Primary Large-Cell Lymphoma of the Testis in a Survey by the International Extranodal Lymphoma Study Group. Journal of Clinical Oncology: Official Journal of the American Society of Clinical Oncology, 21, 20-27. https://doi.org/10.1200/JCO.2003.11.141

[19] Kebudi, A., Coban, A., Yetkin, G., Tanik, C., Uludag, M., Akgun, I., et al. (2005) Primary T-Lymphoma of the Breast with Bilateral Involvement, Unusual Presentation. International Journal of Clinical Practice Supplement, No. 147, 95-98. https://doi.org/10.1111/j.1368-504X.2005.00313.x

[20] Carter, T.R., Feldman, P.S., Innes, D.J., Frierson, H.F. and Frigy, A.F. (1988) The Role of Fine Needle Aspiration Cytology in the Diagnosis of Lymphoma. Acta Cy tologica, 32, 848-853.

[21] Brogi, E. and Harris, N.L. (1999) Lymphomas of the Breast: Pathology and Clinical Behavior. Seminars in Oncology, 26, 357-364.

[22] Wilkinson, E.J., Schuettke, C.M., Ferrier, C.M., Franzini, D.A. and Bland, K.I. (1989) Fine Needle Aspiration of Breast Masses. An Analysis of 276 Aspirates. Acta Cytologica, 33, 613-619. 
[23] Willis, S.L. and Ramzy, I. (1995) Analysis of False Results in a Series of 835 Fine Needle Aspirates of Breast Lesions. Acta Cytologica, 39, 858-864.

[24] Loughrey, M.B., Windrum, P., Catherwood, M.A., Alexander, H.D., Markey, G.M., McManus, D.T., et al. (2004) WHO Reclassification of Breast Lymphomas. Journal of Clinical Pathology, 57, 1213-1214. https://doi.org/10.1136/jcp.2004.018994

[25] Maounis, N., Ellina, E., Papadaki, T., Ioannides, G., Kiale, K., Finokaliotis, N., et al. (2005) Bilateral Primary Lymphoma of the Breast: A Case Report Initially Diagnosed by FNAC. Diagnostic Cytopathology, 32, 114-118. https://doi.org/10.1002/dc.20184

[26] Oya, M., Hirahashi, M., Ochi, M., Hashimoto, M., Ohshima, K., Kikuchi, M., et al. (2009) Spontaneous Regression of Primary Breast Lymphoma. Pathology International, 59, 664-669. https://doi.org/10.1111/j.1440-1827.2009.02424.x

[27] Ogawa, T., Tsuji, E., Shirakawa, K., Hayashibara, N., Kurabayashi, R., Terada, K., et al. (2011) Primary Non-Hodgkin's Lymphoma of the Breast Treated Nonsurgically: Report of Three Cases. Breast Cancer (Tokyo, Japan), 18, 68-72. https://doi.org/10.1007/s12282-009-0107-y

[28] Hugh, J.C., Jackson, F.I., Hanson, J. and Poppema, S. (1990) Primary Breast Lymphoma. An Immunohistologic Study of 20 New Cases. Cancer, 66, 2602-2611. https://doi.org/10.1002/1097-0142(19901215)66:12<2602::AID-CNCR2820661224> 3.0.CO;2-U

[29] Aguilera, N.S., Tavassoli, F.A., Chu, W.S. and Abbondanzo, S.L. (2000) T-Cell Lymphoma Presenting in the Breast: A Histologic, Immunophenotypic and Molecular Genetic Study of Four Cases. Modern Pathology: An Official Journal of the United States and Canadian Academy of Pathology, Inc, 13, 599-605.

https://doi.org/10.1038/modpathol.3880103

[30] Sokolov, T., Shimonov, M., Blickstein, D., Nobel, M. and Antebi, E. (2000) Primary Lymphoma of the Breast: Unusual Presentation of Breast Cancer. The European Journal of Surgery= Acta Chirurgica, 166, 390-393. https://doi.org/10.1080/110241500750008952

[31] Baker, R., Slayden, G. and Jennings, W. (2005) Multifocal Primary Breast Lymphoma. Southern Medical Journal, 98, 1045-1048. https://doi.org/10.1097/01.smj.0000182173.05977.2e

[32] Mason, H.S., Johari, V., March, D.E. and Crisi, G.M. (2005) Primary Breast Lymphoma: Radiologic and Pathologic Findings. The Breast Journal, 11, 495-496. https://doi.org/10.1111/j.1075-122X.2005.00167.x

[33] Babovic, N., Jelic, S. and Jovanovic, V. (2000) Primary Non-Hodgkin Lymphoma of the Breast. Is It Possible to Avoid Mastectomy? Journal of Experimental \& Clinical Cancer Research: $C R, 19,149-154$.

[34] Avilés, A., Delgado, S., Nambo, M.J., Neri, N., Murillo, E. and Cleto, S. (2005) Primary Breast Lymphoma: Results of a Controlled Clinical Trial. Oncology, 69, 256-260. https://doi.org/10.1159/000088333

[35] Choo, S.P., Lim, S.T., Wong, E.H. and Tao, M. (2006) Breast Lymphoma: Favorable Prognosis after Treatment with Standard Combination Chemotherapy. Onkologie, 29, 14-18. https://doi.org/10.1159/000090009

[36] Arber, D.A., Simpson, J.F., Weiss, L.M. and Rappaport, H. (1994) Non-Hodgkin's Lymphoma Involving the Breast. The American Journal of Surgical Pathology, 18, 288-295. https://doi.org/10.1097/00000478-199403000-00009

[37] Ryan, G.F., Roos, D.R. and Seymour, J.F. (2006) Primary Non-Hodgkin's Lymphoma of the Breast: Retrospective Analysis of Prognosis and Patterns of Failure in Two 
Australian Centers. Clinical Lymphoma \& Myeloma, 6, 337-341.

https://doi.org/10.3816/CLM.2006.n.010

[38] Anania, G., Baccarani, U., Risaliti, A., Terrosu, G., Donini, A., Mariuzzi, L., et al. (1997) Primary Non-Hodgkin's T-Cell Lymphoma of the Breast. The European Journal of Surgery = Acta Chirurgica, 163, 633-635.

[39] Coffey, J., Hodgson, D.C. and Gospodarowicz, M.K. (2003) Therapy of Non-Hodgkin's Lymphoma. European Journal of Nuclear Medicine and Molecular Imaging, 30, S28-S36. https://doi.org/10.1007/s00259-003-1157-6

\section{Abbreviations}

Primary breast lymphoma (PBL); Extranodal-lymphoma (ENL); non-Hodgkin's Lymphoma (NHL); Cyclophosphamide, Doxorubicin, Vincristine and Prednisolone (CHOP); Fine-needle aspiration cytology (FNAC) 